\title{
Produtividade da cana-de-açúcar após o cultivo de leguminosas
}

\author{
Edmilson José Ambrosano (1*); Heitor Cantarella ( $\left.{ }^{2}\right)$; Gláucia Maria Bovi Ambrosano ( $\left.{ }^{3}\right)$; Eliana \\ Aparecida Schammas ( ${ }^{4}$ ); Fábio Luis Ferreira Dias ('); Fabrício Rossi (5); Paulo Cesar Ocheuze \\ Trivelin ( $\left.{ }^{6}\right)$; Takashi Muraoka ( $\left.{ }^{6}\right)$; Raquel Castellucci Caruso Sachs ( $\left.{ }^{7}\right)$; Rozario Azcón $\left({ }^{7}\right.$ )
}

(1) APTA, Pólo Regional Centro-Sul, Caixa Postal 28, 13400-970 Piracicaba (SP), Brasil.

(2) Instituto Agronômico (IAC), Caixa Postal 28, 13001-970 Campinas (SP), Brasil.

(3) Universidade Estadual de Campinas, Departamento de Odontologia Social, Caixa Postal 52, 13414-903 Piracicaba (SP) Brasil.

(4) Instituto de Zootecnia, Caixa Postal 60, 13460-000 Nova Odessa (SP), Brasil.

(5) Bolsista de Pós-Doc. da FAPESP junto a APTA, Pólo Regional Centro Sul, Caixa Postal 28, 13400-970 Piracicaba (SP), Brasil

${ }^{(6)}$ Centro de Energia Nuclear na Agricultura (CENA/USP), Caixa Postal 96, 13400-970 Piracicaba (SP), Brasil.

(') Estação Experimental de Zaidin, Profesor Albareda, 1, 18008 Granada, Espanha.

(*) Autor correspondente: ambrosano@apta.sp.gov.br

Recebido: 24/nov./2010; Aceito: 11/maio/2011

\section{Resumo}

Estudou-se o efeito do cultivo prévio de leguminosas sobre a produtividade e lucratividade da cana-de-açúcar. Foram determinados a produtividade de biomassa, o acúmulo de nutrientes das leguminosas, a ocorrência natural de fungos micorrízicos arbusculares, bem como o efeito das leguminosas sobre a população de nematoides do gênero Pratylenchus à cana-deaçúcar. O experimento foi desenvolvido em Piracicaba (SP), Brasil, em solo classificado como Argissolo Vermelho-Amarelo distrófico, utilizando-se a cultivar de cana-de-açúcar (Saccharum spp.) IAC87-3396. As avaliações dos efeitos do cultivo prévio das leguminosas foram realizadas durante cinco cortes consecutivos. Os tratamentos consistiram do cultivo prévio das leguminosas: Amendoim (Arachis hypogaea L) - cultivares IAC-Tatu e IAC-Caiapó, crotalária júncea IAC 1 (Crotalaria juncea L) e mucuna preta [Mucuna aterrima (Piper \& Tracy) Holland], e um tratamento-testemunha. Adotou-se o delineamento em blocos casualizados com cinco repetições. A leguminosa mais produtiva de biomassa seca (parte aérea+raízes) foi a crotalária júncea IAC 1 (10.264 kg ha-1), seguida da mucuna preta (4.391 kg ha-1) e dos amendoins, IAC-Caiapó (3.177 kg ha-1) e IAC-Tatu (1.965 $\left.\mathrm{kg} \mathrm{ha}^{-1}\right)$. O amendoim IAC-Caiapó e a mucuna preta foram as espécies mais infectadas por fungos micorrízicos. 0 amendoim, independente da cultivar, foi a leguminosa que mais reduziu a infestação de Pratylenchus spp. na cana-de-açúcar. Após cinco cortes da cana-de-açúcar o melhor desempenho foi notado no tratamento com cultivo prévio de crotalária júncea IAC 1, o qual promoveu incrementos de 30\% e 35\% na produtividade de colmos e de açúcar respectivamente e o melhor desempenho econômico.

Palavras-chave: Saccharum spp., Arachis hypogaea L., Crotalaria juncea L., Mucuna aterrima (Piper \& Tracy) Holland, Pratylenchus spp., adubos verdes.

\section{Productivity of sugarcane after previous legumes crop}

\section{Abstract}

The research aimed to evaluate and characterize the biomass of leguminous residues, the natural arbuscular mycorrhizal (AM) fungus occurrence and the effect of leguminous on the nematodes (Pratylenchus spp.) in sugarcane crop. The experiment was carried out in Piracicaba, São Paulo State, Brazil. The soil was classified as Paleudalf and the sugarcane (Saccharum spp.) Cultivar was IAC87-3396. The effects of previous cultivation of legumes were evaluated for five consecutive harvests. The treatments consisted of previous cultivation of legumes: peanut (Arachis hypogaea L.) cultivars IAC-Tatu and IAC-Caiapó, sunn hemp IAC 1 (Crotalaria juncea L.) and velvet-bean [Mucuna aterrima (Piper \& Tracy) Holland], and a control treatment. We adopted the randomized block design with five replications. The legume most productive was sunn hemp IAC 1 with $10.264 \mathrm{~kg} \mathrm{ha}^{-1}$, followed by velvet-bean with $4.391 \mathrm{~kg} \mathrm{ha}^{-1}$ and peanuts IAC-Caiapó and IAC-Tatu with $3.177 \mathrm{~kg}$ ha-1 and $1.965 \mathrm{~kg} \mathrm{ha}^{-1}$, respectively. The peanut IAC-Caiapó and velvet bean were the leguminous crops that resulted in the greater percentage of AM fungus. The lowest population of Pratylenchus spp. was found in the treatments with peanut IAC-Tatu and IAC-Caiapó. After five harvests, sunn hemp was the leguminous crop that induced the greatest sugarcane yield, with $30 \%$ increase in cane yield and 35\% in sugar yield.

Key words: Saccharum spp., Arachis hypogaea L., Crotalaria juncea L., Mucuna aterrina (Piper \& Tracy) Holland, Pratylenchus spp., green manure. 


\section{INTRODUÇÃO}

A utilização de plantas na reciclagem dos nutrientes e manutenção da fertilidade do solo, associadas às técnicas do plantio direto e do cultivo mínimo são opçôes para a obtenção de eficiência produtiva e conservação do solo e da água (Ambrosano et al., 1999).

Em função de seu potencial de fixação de nitrogênio e recuperação da fertilidade do solo, as leguminosas (Fabaceae) representam uma alternativa ao suprimento, substituiçáo ou complementação da adubação mineral e recomposição da fertilidade do solo (ScivitTaro et al., 2000).

A utilização da adubação verde com leguminosas na cana-de-açúcar é recomendada quando se reforma o canavial. Essa prática não interfere na brotação da cana. Seu custo é relativamente baixo e promove aumentos significativos nas produçóes de cana e de açúcar em pelo menos dois cortes. Adicionalmente, protege o solo contra a erosão e evita multiplicação de plantas espontâneas (Ambrosano et al.,2005).

Com a prática da adubação verde, é possível recuperar a fertilidade do solo proporcionando aumento da capacidade de troca de cátions e da disponibilidade de macro e micronutrientes; formação e estabilização de agregados; melhoria da infiltração de água e aeraçáo; diminuição diuturna da amplitude de variação térmica; controle dos nematoides e, no caso das leguminosas, incorporação ao solo do nutriente nitrogênio, efetuada através da fixação biológica (Igue, 1984).

Com relação aos nematoides das lesões radiculares, existem poucos trabalhos que relatam estudos do efeito de C. juncea sobre esses nematoides (WANG et al., 2002; Inомото et al., 2006, MAсHADo et al., 2007). Existe, atualmente, demanda crescente por métodos alternativos no controle de nematoides. Tal demanda visa à substituição do controle químico, devido às implicaçôes toxicológicas e ambientais negativas que acarretam, além do crescente interesse pelo cultivo da cana-de-açúcar, em sistema orgânico de produção, pelo mercado interno e externo.

$\mathrm{O}$ presente estudo tem como objetivos quantificar a produtividade dos adubos verdes e amendoins em cultivo prévio à cana-de-açúcar e a quantidade de nitrogênio fixado por elas, medir a infestação na cana-de-açúcar por nematoides bem como a produtividade física e do açúcar e a lucratividade da cana-de-açúcar cultivada em cinco cortes após o cultivo de leguminosas.

\section{MATERIAL E MÉTODOS}

O experimento foi desenvolvido em Piracicaba, SP (22 $2^{\circ} 2^{\prime} \mathrm{S}, 47^{\circ} 38^{\prime} \mathrm{W}$ e $560 \mathrm{~m}$ de altitude), Brasil. O solo, classificado como Argissolo Vermelho-Amarelo distrófico, foi caracterizado quimicamente, em diferentes profundidades após o corte dos adubos verde, antes do plantio da cana-de-açúcar. Não foi realizada correção química do solo para cultivo dos adubos verdes.

Apesar de constatada a necessidade da correção da acidez do solo através da observaçáo da analise de solo (Tabela 1), seguiu-se a recomendação de MasCARENHAS et al. (1994) quando afirmaram que as leguminosas respondem mais à fertilidade natural do solo do que à adubação direta. $\mathrm{O}$ experimento foi desenvolvido sem essa correção e sem adubação, e dessa forma, as leguminosas puderam expressar seu potencial de produção. Essas condições de solo foram semelhantes às observadas por Ambrosano et al. (2011) em solo com V\% de 22, onde a crotalária júncea produziu $9 \mathrm{Mg} \mathrm{ha}^{-1}$ de material vegetal seco.

A rotação da cana-de-açúcar foi feita com três leguminosas: Amendoim (Arachis hypogaea L.) - cultivares IAC-Tatu e IAC-Caiapó, crotalária júncea (Crotalaria juncea L.), cultivar IAC 1 e mucuna preta [Mucuna aterrina (Piper \& Tracy) Holland], e um tratamento testemunha. Cada parcela das plantas leguminosas foi constituída por 14 linhas de 10 metros de comprimento, espaçadas de $0,50 \mathrm{~m}$ entre si. Adotou-se o delineamento em blocos casualizados com cinco repetiçóes.

As leguminosas foram semeadas em dezembro de 1999 e após 30 dias foi efetuada capina manual para eliminação das plantas daninhas. Após 120 dias, a partir da emergência, procedeu-se ao corte e à deposição da massa vegetal natural na superfície do solo, sem incorporação. Nessa ocasião, foi amostrado o solo para caracterizaçáo química da fertilidade, em duas profundidades (Tabela 1). Foram amostradas, também, as raízes das leguminosas para avaliação da porcentagem de colonização natural dos fungos micorrizicos arbusculares FMAs.

O nível de colonização micorrízica foi estimado após a coloração das raízes, segundo Philips e Hyman (1970). A determinaçáo da porcentagem de colonização das raízes pelo fungo micorrízico foi feita por observaçáo em microscópio ótico com auxílio de uma placa reticulada, segundo método proposto por Giovanetti e Mosse, 1980.

A produtividade do material vegetal natural dos adubos verdes e de grãos dos amendoins utilizados em rotação

Tabela 1. Característica do solo empregado no experimento, após o corte do adubo verde, antes do plantio da cana-de-açúcar (Piracicaba, 1999-2005)

\begin{tabular}{|c|c|c|c|c|c|c|c|c|c|c|}
\hline \multirow{2}{*}{$\begin{array}{l}\text { Camadas } \\
\text { (cm) }\end{array}$} & \multirow{2}{*}{$\begin{array}{c}\text { Mo } \\
\left(\mathrm{g} \mathrm{dm}^{-3}\right)\end{array}$} & \multirow[t]{2}{*}{$\underset{\mathrm{CaCl}_{2}}{\mathrm{pH}}$} & $\begin{array}{c}P \\
\text { resina }\end{array}$ & $\mathbf{K}$ & $\mathrm{Ca}$ & $\mathrm{Mg}$ & $\mathrm{H}+\mathrm{Al}$ & SB & CTC & v \\
\hline & & & $\left(\mathrm{mg} \mathrm{dm}^{-3}\right)$ & \multicolumn{6}{|c|}{$\left(\mathrm{mmol}_{\mathrm{c}} \mathrm{dm}^{-3}\right)$} & $(\%)$ \\
\hline $0-20$ & 22,2 & 4,6 & 12,8 & 1,3 & 10,0 & 6,8 & 52,0 & 18,1 & 70,3 & 25,6 \\
\hline $20-40$ & 20,4 & 4,5 & 10,4 & 0,8 & 9,4 & 6,8 & 53,2 & 17,0 & 70,3 & 24,2 \\
\hline
\end{tabular}


com cana-de-açúcar também foram avaliados, amostrandose uma área central correspondente a duas linhas de $2 \mathrm{~m}$ de comprimento. Desse material, uma amostra foi retirada para determinaçáo de umidade em estufa de circulaçáo forçada de ar a uma temperatura de $60^{\circ} \mathrm{C}$. Esse material vegetal seco foi moído, em moinho Willey, e utilizado para as determinaçóes químicas de teores de elementos nutrientes, segundo Bataglia et al. (1983). A abundância natural de ${ }^{15} \mathrm{~N}$, e teores de carbono, foram determinados em espectrômetro de massa, segundo Trivelin et al. (1973) e metodologia de (Shearer e Kohl, 1986). A partir desses valores, estimou-se a porcentagem de nitrogênio vindo da fixação biológica do nitrogênio $\left(\delta^{15} \mathrm{~N}\right)$, utilizando-se do girassol IAC-Uruguai, como planta controle, não nodulante.

Após o corte dos adubos verdes foi plantada a cana-deaçúcar (variedade IAC87-3396), no espaçamento de 1,40 m entre fileiras de plantas. A cana-de-açúcar foi adubada com $500 \mathrm{~kg} \mathrm{ha}^{-1}$ da formulaçáo 08-28-16 $\left(\mathrm{N}, \mathrm{P}_{2} \mathrm{O}_{5}, \mathrm{~K}_{2} \mathrm{O}\right)$ no plantio, e após cada corte, aplicaram-se $500 \mathrm{~kg} \mathrm{ha}^{-1}$ da formulaçáo 20-5-20 (N, $\left.\mathrm{P}_{2} \mathrm{O}_{5}, \mathrm{~K}_{2} \mathrm{O}\right)$. Não se utilizou irrigação e o controle de plantas daninhas foi efetuado após cada corte da cana-deaçúcar aplicando-se o herbicida metribuzin $\left(1,92 \mathrm{~L} \mathrm{ha}^{-1}\right)$.

A cana planta foi colhida aos 18 meses em 25 de outubro de 2001. As socas foram colhidas com periodicidade de aproximadamente 12 meses em: 9/7/2002, 1.\%/8/2003, $7 / 11 / 2004$ e 6/10/2005. Nas colheitas, foram determinadas as massas de uma amostra de cana-de-açúcar coletadas em três segmentos de $2 \mathrm{~m}$ lineares contínuos, no centro da parcela experimental. A partir dessas massas, calculou-se a produtividade de colmos por hectare (TCH).

Foram colhidas também amostras de dez colmos de cana seguidos na linha em cada tratamento (ТАлімото, 1964) para análise de sólidos solúveis ( ${ }^{\circ}$ Brix) e sacarose aparente (pol\%). Calculou-se a tonelada de açúcar aparente por hectare, i.e. pol por hectare (TPH).

Foram escolhidos aleatoriamente três pontos, nas três linhas centrais de cada parcela, em seguida, retirava-se a touceira de cana-de-açúcar e coletavam-se $100 \mathrm{~g}$ de raízes. Essas amostras foram levadas ao laboratório para processamento imediato, de acordo com Coolen e D'Herde (1972) e Jenkins (1964). A suspensão obtida após a extração, contendo os nematoides, foi acondicionada em frasco de vidro contendo soluçáo de Golden (Hooper, 1970) para posterior contagem e identificação.

Para a análise econômica do experimento foram considerados os custos de produção da cana-de-açúcar, do amendoim - cultivares IAC-Caiapó e IAC-Tatu, crotalária júncea IAC 1 e mucuna preta, além das receitas obtidas com a venda da cana-de-açúcar (cinco cortes) e dos amendoins (colheita única feita na área de reforma).

O custo de produção para a cana-de-açúcar foi uma média dos valores fornecidos pelas cooperativas da regiáo de Piracicaba, considerando as etapas de sistematização da área, preparo do solo, plantio e tratos culturais da cana planta e da cana soca. O custo referente ao corte, carregamento e transporte foi calculado com base na produtividade do experimento e no valor médio fornecido pelas usinas da região de Piracicaba. Esses custos foram referentes ao mês de abril de 2010.

O cálculo da receita com a venda da cana-de-açúcar para os cinco cortes foi feito com base no preço cana esteira referente a abril de 2010, divulgado pela União dos Produtores de Bioenergia (UDOP, 2010) e a produtividade do experimento.

Para os adubos verdes, crotalária júncea IAC 1 e mucuna preta, os custos de produção foram calculados considerando o valor da semente fornecido por uma empresa de sementes sediada em Piracicaba e os coeficientes técnicos das operaçóes de plantio e manejo da biomassa retirados de LuZ et al. (2005). O valor do custo hora/máquina foi obtido junto a Secretaria Municipal de Agricultura e Abastecimento de Piracicaba.

Os custos do amendoim IAC-Caiapó e IAC-Tatu foram retirados de Martins (2010) e os preços médios recebidos pelos produtores para o cálculo da receita com a venda dos amendoins publicados pelo Instituto de Economia Agrícola (Banco IEA, 2010) referentes ao mês de abril de 2010 e produtividade do experimento.

Para os dados de micorrizas, produção de massa das leguminosas e amendoins, e produção de grãos foram adotados o delineamento experimental de blocos casualizados, com cinco repetiçóes e cinco tratamentos. As médias de tratamentos foram comparadas através do teste de Tukey $(\alpha=0,05)$ e $(\alpha=0,10)$ para a análise de custo. Para efeito de análise de variância dos dados produtividade das plantas adubos verdes e amendoins e extração de alguns nutrientes, foram transformados em $\log (\mathrm{X})$ uma vez que as pressuposiçóes do modelo matemático não foram atendidas.

Para os dados de produtividade (TCH e TPH), utilizouse o delineamento de parcelas subdivididas no tempo, pois pelo teste de esfericidade de Mauchly (1940), verificouse que a matriz de covariância atendia a condição de H-F, Huynh e Feldt (1970), necessária para que o teste F da análise de variância de parcelas subdivididas no tempo, seja válido. Assim os dados foram analisados por meio de análise de variância e as médias comparadas pelo teste de Tukey $(\alpha=0,05)$.

O número de nematoides Pratylenchus spp. apresentou distribuição bastante assimétrica. Essa variável foi analisada por meio de estatística descritiva e gráfico Box plot. Todas as análises foram realizadas no programa estatístico SAS 8.2 (SAS, 2004).

\section{RESULTADOS E DISCUSSÃO}

No Brasil o uso dos adubos verdes em áreas de reforma do canavial é bastante antigo, sendo iniciado na década de 1950, por Cardoso e Souza, que observaram incremento na produção agrícola e de açúcar, destacando-se 
a crotalária júncea como o melhor adubo verde para promover esse benefício (Ambrosano et al., 2005).

\section{Produção de massa vegetal e caracterização química das plantas utilizadas no pré-cultivo da cana-de-açúcar}

Observa-se grande produtividade de material vegetal seco da crotalária júncea IAC 1 , seguida da mucuna preta, amendoim IAC-Caiapó e amendoim IAC-Tatu (Tabela 2).

A produtividade resultante desse experimento está acima da avaliada por CACERES e AlCARDE (1995) que verificaram produtividade de 7 e 3 toneladas por hectare para crotalária júncea e mucuna preta respectivamente. Produçôes semelhantes foram analisadas por Ambrosano et al., 2010, com produtividade de 6 e 5 toneladas por hectare, respectivamente, para crotalária júncea e mucuna preta. Esse fato indica que a produtividade atingida no experimento pode ser facilmente reproduzida pelos agricultores, desde que respeitado o limite máximo de dezembro para semeadura das leguminosas.

Não houve diferença na produtividade de grãos das cultivares de amendoins (Tabela 2). Quaggio e Godor (1996) consideraram, para o Estado de São Paulo, três classes de produtividade para o amendoim em sistema convencional: baixa - menor que $1.500 \mathrm{~kg} \mathrm{ha}^{-1}$; média - entre 1.500 e $3.000 \mathrm{~kg} \mathrm{ha}^{-1}$; e alta - maior que 3.000 $\mathrm{kg} \mathrm{ha}^{-1}$. A produtividade obtida no experimento foi baixa (Tabela 2), contudo o fato de se produzir grãos nesse sistema pode gerar uma renda extra ao produtor que pode ser importante dentro do sistema.
A baixa produtividade pode estar associada à falta de correção e ou adubação química anterior à semeadura dos amendoins, que por serem plantas mais exigentes em nutrientes não expressaram seu potencial produtivo máximo de gráos. Segundo Quaggio e Godor (1996), deve-se aplicar calcário para elevar a saturação por bases a $60 \%$ e, de acordo com a análise inicial do solo, recomenda-se aplicar a quantidade de 80 e $40 \mathrm{~kg} \mathrm{ha}^{-1}$ de $\mathrm{P}_{2} \mathrm{O}_{5}$ e $\mathrm{K}_{2} \mathrm{O}$ respectivamente, para se obter produtividade de mais de 3,0 toneladas por hectare.

Ambrosano et al. (2010) também observaram produtividades baixas para as mesmas cultivares de amendoins quando trabalharam com o mesmo tipo de solo e em sistema de pré-cultivo. Os autores efetuaram uma análise econômica da rotaçáo com amendoim e notaram elevado custo de produção para esta espécie e sua renda liquida foi comparada ao tratamento testemunha, sem pré-cultivo.

Os mesmos autores verificaram renda liquida acima do tratamento testemunha, sem fazer rotação, para as espécies crotalária júncea, mucuna preta, soja e feijão mungo. $\mathrm{O}$ fato de demonstrar que a adubaçáo verde aumenta a renda liquida do produtor incentiva cada vez mais a utilização de rotação nas áreas de reforma do canavial.

Quando se trabalha com adubação verde, uma das características importantes de se levantar é a relação carbono nitrogênio $\mathrm{C} / \mathrm{N}$ e no caso das leguminosas, a porcentagem de nitrogênio presente na planta que veio da fixação biológica do nitrogênio e suas relaçôes com micorrizas existentes naturalmente no solo. No experimento a relação $\mathrm{C} / \mathrm{N}$ foi baixa, em torno de 17, observada nas leguminosas amendoim IAC-Caiapó e mucuna preta com os menores resultados e o amendoim IAC-Tatu e a crotalária júncea com valores maiores, contudo abaixo de 25 (Tabela 3).

Tabela 2. Rendimentos de material verde e seco $\left(\mathrm{kg} \mathrm{ha}^{-1}\right)$ das leguminosas e do amendoim sem casca, utilizadas em cultivo prévio à canade-açúcar (Piracicaba, 1999-2005)

\begin{tabular}{lcccccc} 
& \multicolumn{2}{c}{ Parte aérea } & \multicolumn{2}{c}{ Raízes } & \multicolumn{2}{c}{ Sementes } \\
\cline { 2 - 5 } Tratamentos & Material verde ${ }^{(1)}$ & Material seco & Material verde & Material seco ${ }^{(2)}$ & Material seco \\
\hline Amendoim IAC-Caiapó & $9100 \mathrm{~b}$ & $2696 \mathrm{bc}$ & $1912 \mathrm{~b}$ & $481 \mathrm{~b}$ & $1298 \mathrm{a}$ \\
\hline Crotalária júncea IAC 1 & $24700 \mathrm{a}$ & $9318 \mathrm{a}$ & $2880 \mathrm{a}$ & $946 \mathrm{a}$ & --- \\
\hline Amendoim IAC-Tatu & $3000 \mathrm{c}$ & $1604 \mathrm{c}$ & $1271 \mathrm{c}$ & $361 \mathrm{c}$ & $1223 \mathrm{a}$ \\
\hline Mucuna preta & $17100 \mathrm{ab}$ & $4130 \mathrm{~b}$ & $1205 \mathrm{c}$ & $261 \mathrm{~d}$ & --- \\
\hline CV(\%) & 3,65 & 22,48 & 15,40 & 6,73 & 29,23 \\
\hline
\end{tabular}

Valores 1 e 2 sáo médias transformadas em $\log (\mathrm{x})$ e raiz quadrada de (x) respectivamente. Médias seguidas de letras diferentes nas colunas diferem entre si, pelo teste de Tukey ( $\mathrm{p} \leq 0,05)$.

Tabela 3. Infecção natural de fungos micorrízicos arbusculares, acúmulo de carbono e nitrogênio, relação C:N e $\mathrm{N}$ obtido da fixação biológica (N-FBN) nas leguminosas cultivadas anteriormente a cana-de-açúcar (Piracicaba, 1999-2005)

\begin{tabular}{lcccccc} 
Culturas utilizadas no pré & Micorrizas arbusculares & $\mathbf{C}$ & $\mathbf{N}$ & \multicolumn{2}{c}{$\mathbf{C}: \mathbf{N}$} & $\mathbf{N}-F B N$ \\
cultivo a cana & $\mathbf{( \% )}$ & $\mathbf{( \mathbf { g ~ k g } ^ { - 1 } )}$ & $\mathbf{( \mathbf { g ~ k g } ^ { - 1 } )}$ & & $\mathbf{( \% )}$ \\
\hline Amendoim IAC-Caiapó & $53 \mathrm{a}$ & $424 \mathrm{a}$ & $29 \mathrm{~b}$ & $15 \mathrm{~b}$ & $70 \mathrm{a}$ \\
\hline Crotalária júncea IAC 1 & $53 \mathrm{a}$ & $449 \mathrm{a}$ & $23 \mathrm{~b}$ & $20 \mathrm{a}$ & $69 \mathrm{a}$ \\
\hline Amendoim IAC-Tatu & $43 \mathrm{a}$ & $440 \mathrm{a}$ & $18 \mathrm{~b}$ & $24 \mathrm{a}$ & $38 \mathrm{~b}$ \\
\hline Mucuna preta & $54 \mathrm{a}$ & $446 \mathrm{a}$ & $42 \mathrm{a}$ & $11 \mathrm{~b}$ & $62 \mathrm{a}$ \\
\hline Média & 51 & 440 & 28 & 17 & 60 \\
\hline CV(\%) & 12,68 & 2,80 & 19,08 & 19,55 & 13,68
\end{tabular}

Médias seguidas de letras diferentes nas colunas diferem entre si, pelo teste de Tukey $(\mathrm{p} \leq 0,05)$. 
A maioria dos pesquisadores considera que se a relação $\mathrm{C} / \mathrm{N}$ está na faixa de 10 a 12:1 ocorre liberaçáo de $\mathrm{N}$ da matéria orgânica do solo. Com relação a resíduos orgânicos, entre 25 e 35: 1 ocorre decomposição sem imobilização de $\mathrm{N}$ do solo e acima desses valores, há imobilização.

Esta baixa relação avaliada faz com que o material se decomponha muito rapidamente e seus nutrientes fiquem rapidamente disponíveis. Ressalta-se, entretanto, que esses processos ocorrem no solo simultaneamente, podendo ocorrer reimobilização e remineralização do mesmo "pool" de N.

Contudo, a grande desvantagem dessa rápida decomposição é a dificuldade de formar palha na superfície devido à rápida degradação do material vegetal.

As plantas utilizadas em rotação com a cana-de-açúcar, à exceção do amendoim IAC-Tatu, representam mais da metade de seu sistema radicular infectado naturalmente por fungos micorrízicos arbusculares (Tabela 3). Trabalhos desenvolvidos por Panja e Chaudhuri (2004) têm mostrado a importância do pré-plantio de leguminosas para o enriquecimento de micorrizas em solo de viveiro de laranja.

Os baixos valores observados de N-FBN para o amendoim IAC-Tatu (Tabela 3) podem decorrer do fato da amostragem ter sido feita aos 120 dias após a semeadura. Nessa fase, a planta estava em fase adiantada de maturaçáo das vagens e grande parte do nitrogênio já translocados para os grãos.

Perin et al. (2006) determinaram a quantidade de nitrogênio fixado pela crotalária júncea em um sistema de rotação com milho; verificaram uma quantidade substancial de nitrogênio vindo da fixação biológica (FBN) presente na parte aérea da crotalária júncea $(57 \%)$, quando cultivada isoladamente e $61 \%$ quando crescida consorciada com milheto (na proporçáo de sementes de 50\% + 50\%). Esses resultados sáo concordantes com os obtidos nesse estudo, em que $C$. juncea fixou em torno de $69 \%$ do total de seu nitrogênio.

De modo geral, os amendoins proporcionaram maiores teores de nutrientes para parte aérea que no sistema radicular em comparação com a mucuna preta e a crotalária júncea (Tabela 4). Entretanto, a quantidade aportada ao sistema (conteúdo de nutrientes) foi a menor uma vez que eles tiveram as menores produçôes de massa seca (Tabela 5). Todavia, o conteúdo de boro, de ferro e de manganês foram maiores nos amendoins, indicando que são plantas acumuladoras de micronutrientes e importantes na sua reciclagem.

Tabela 4. Teores de macro $\left(\mathrm{g} \mathrm{kg}^{-1}\right)$ e micronutrientes $\left(\mathrm{mg} \mathrm{kg}^{-1}\right)$ nas leguminosas cultivadas anteriormente à cana-de-açúcar (Piracicaba, 1999-2005)

\begin{tabular}{|c|c|c|c|c|c|c|c|c|c|c|}
\hline \multirow{2}{*}{$\begin{array}{l}\text { Culturas utilizadas no } \\
\text { pré-cultivo à cana }\end{array}$} & \multicolumn{10}{|c|}{ Parte aérea } \\
\hline & $\mathbf{N}$ & $\mathbf{P}$ & K & $\mathrm{Ca}$ & $\mathrm{Mg}^{(1)}$ & $\mathbf{B}^{(1)}$ & $\mathrm{Cu}$ & $\mathrm{Fe}^{(1)}$ & Mn & Zn \\
\hline Amendoim IAC-Caiapó & $29,3 \mathrm{~b}$ & $2,1 \mathrm{~b}$ & $12,6 \mathrm{a}$ & $14,1 \mathrm{a}$ & $7,6 \mathrm{~b}$ & $91 \mathrm{a}$ & 8 bc & $2263 \mathrm{a}$ & $255 \mathrm{a}$ & $29 \mathrm{a}$ \\
\hline Crotalária júncea IAC 1 & $23,3 b c$ & 1,7 bc & $8,3 b$ & $7,7 \mathrm{~b}$ & $3,6 \mathrm{c}$ & $32 c$ & 8 bc & $283 b$ & $79 \mathrm{~b}$ & $26 a b$ \\
\hline Amendoim IAC-Tatu & $17,9 \mathrm{c}$ & $1,3 c$ & $13,8 \mathrm{a}$ & $15,5 \mathrm{a}$ & 9,3 a & $61 \mathrm{~b}$ & $6 c$ & $1882 \mathrm{a}$ & $182 \mathrm{ab}$ & $21 \mathrm{~b}$ \\
\hline Mucuna preta & $42,1 \mathrm{a}$ & $3,0 \mathrm{a}$ & $12,0 a b$ & $6,9 \mathrm{~b}$ & $2,5 \mathrm{~d}$ & $35 c$ & $14 \mathrm{a}$ & $307 \mathrm{~b}$ & $194 a b$ & $26 a b$ \\
\hline \multirow[t]{3}{*}{ CV(\%) } & 16,51 & 18,31 & 18,11 & 12,5 & 6,38 & 8,8 & 8,50 & 52,0 & 36,9 & 10,93 \\
\hline & \multicolumn{10}{|c|}{ Raízes } \\
\hline & $\mathbf{N}$ & $\mathbf{P}$ & $\mathbf{K}$ & $\mathrm{Ca}$ & Mg & B & $\mathrm{Cu}$ & $\mathrm{Fe}^{(1)}$ & $M n$ & Zn \\
\hline Amendoim IAC-Caiapó & $13,4 \mathrm{~b}$ & $1,0 \mathrm{~b}$ & $10,1 a b$ & $7,1 \mathrm{~b}$ & $3,7 \mathrm{a}$ & $163 \mathrm{a}$ & $10 \mathrm{bc}$ & $4518 a b$ & $114,2 \mathrm{a}$ & $26,4 \mathrm{a}$ \\
\hline Crotalária júncea IAC 1 & $8,2 \mathrm{c}$ & $0,5 \mathrm{c}$ & $8,0 \mathrm{~b}$ & $1,6 \mathrm{c}$ & $1,4 b$ & $152 \mathrm{ab}$ & $9 \mathrm{c}$ & 7582 a & $97,4 a$ & $16,1 \mathrm{~b}$ \\
\hline Amendoim IAC-Tatu & $11,8 \mathrm{~b}$ & 0,8 bc & $11,2 \mathrm{a}$ & $8,4 \mathrm{a}$ & $3,8 \mathrm{a}$ & $108 \mathrm{bc}$ & $12 b$ & $4475 a b$ & $103,0 \mathrm{a}$ & $27,3 \mathrm{a}$ \\
\hline Mucuna preta & $18,9 \mathrm{a}$ & $1,4 \mathrm{a}$ & $8,6 b$ & $5,7 d$ & $3,7 \mathrm{a}$ & $91 \mathrm{c}$ & $20 a$ & 3087 b & $91,0 \mathrm{a}$ & $30,9 a$ \\
\hline CV(\%) & 7,34 & 16,93 & 13,91 & 8,05 & 16,76 & 21,20 & 13,1 & 34,0 & 26,0 & 16,5 \\
\hline
\end{tabular}

( $\left.{ }^{1}\right)$ Médias transformadas em $\log (\mathrm{x})$. Médias seguidas de letras diferentes nas colunas diferem entre si, pelo teste de Tukey ( $\left.\mathrm{p} \leq 0,05\right)$.

Tabela 5. Acúmulo de macro $\left(\mathrm{kg} \mathrm{ha}^{-1}\right)$ e micronutrientes $\left(\mathrm{g} \mathrm{ha}^{-1}\right)$ nas leguminosas cultivadas anteriormente à cana-de-açúcar (Piracicaba, 1999-2005)

\begin{tabular}{|c|c|c|c|c|c|c|c|c|c|c|}
\hline \multirow{2}{*}{$\begin{array}{l}\text { Culturas utilizadas no } \\
\text { pré-cultivo à cana }\end{array}$} & \multicolumn{10}{|c|}{ Parte aérea } \\
\hline & $\mathbf{N}$ & $\mathbf{P}$ & K & $\mathrm{Ca}$ & $\mathbf{M g}^{(1)}$ & $\mathbf{B}^{(1)}$ & $\mathrm{Cu}$ & $\mathrm{Fe}^{(1)}$ & Mn & Zn \\
\hline Amendoim IAC-Caiapó & $83,4 \mathrm{~b}$ & $5,9 \mathrm{~b}$ & 33,9 bc & $37,9 \mathrm{~b}$ & $20,5 b$ & $232 a b$ & $23 \mathrm{~b}$ & 5393 a & $687 a b$ & $81 \mathrm{~b}$ \\
\hline Crotalária júncea IAC 1 & 220,9 a & $15,7 \mathrm{a}$ & 76,5 a & $72,6 \mathrm{a}$ & $33,4 \mathrm{a}$ & $304 \mathrm{a}$ & $80 \mathrm{a}$ & 2581 bc & $935 \mathrm{a}$ & $250 \mathrm{a}$ \\
\hline Amendoim IAC-Tatu & $29,5 b$ & $2,1 \mathrm{c}$ & $22,0 \mathrm{c}$ & $25,1 \mathrm{~b}$ & 14,8 bc & $100 \mathrm{c}$ & $11 \mathrm{~b}$ & 3054 b & $303 b$ & $35 c$ \\
\hline Mucuna preta & 179,8 a & $13,0 \mathrm{ab}$ & $48,0 \mathrm{~b}$ & $31,1 \mathrm{~b}$ & $10,7 \mathrm{c}$ & $150 \mathrm{bc}$ & $60 \mathrm{a}$ & $1439 c$ & $808 \mathrm{a}$ & $111 \mathrm{~b}$ \\
\hline \multirow[t]{3}{*}{$\mathrm{CV}(\%)$} & 38,2 & 23,4 & 24,2 & 31,9 & 25,8 & 26,0 & 33,8 & 32,0 & 44,9 & 31,7 \\
\hline & \multicolumn{10}{|c|}{ Raízes } \\
\hline & $\mathbf{N}$ & $\mathbf{P}$ & K & $\mathrm{Ca}$ & Mg & B & $\mathrm{Cu}$ & $\mathrm{Fe}^{(1)}$ & Mn & Zn \\
\hline Amendoim IAC-Caiapó & $7,1 \mathrm{ab}$ & $0,5 \mathrm{a}$ & $4,7 \mathrm{~b}$ & $3,2 \mathrm{a}$ & $1,8 \mathrm{a}$ & 77 b & $4,7 \mathrm{~b}$ & $2140 \mathrm{~b}$ & $54,6 \mathrm{ab}$ & $12,5 a b$ \\
\hline Crotalária júncea IAC 1 & $7,7 \mathrm{a}$ & $0,5 \mathrm{a}$ & $7,6 \mathrm{a}$ & $1,5 b$ & $1,4 a b$ & $145 \mathrm{a}$ & $8,5 \mathrm{a}$ & 7299 a & 93,9 a & $15,2 \mathrm{a}$ \\
\hline Amendoim IAC-Tatu & $4,3 c$ & $0,3 b$ & $4,0 \mathrm{~b}$ & $3,0 \mathrm{a}$ & $1,4 a b$ & $40 c$ & $4,3 b$ & 1643 b & 36,4 bc & $9,8 b$ \\
\hline Mucuna preta & $5,0 \mathrm{bc}$ & $0,4 a b$ & $2,1 \mathrm{c}$ & $1,5 b$ & $1,0 \mathrm{~b}$ & $23 d$ & $5,2 b$ & $818 c$ & $24,1 \mathrm{c}$ & $7,8 \mathrm{~b}$ \\
\hline CV(\%) & 19,26 & 24,05 & 16,24 & 13,30 & 23,50 & 5,7 & 15,7 & 5,0 & 9,7 & 24,4 \\
\hline
\end{tabular}

(') Médias transformadas em $\log (\mathrm{x})$. Médias seguidas de letras diferentes nas colunas diferem entre si, pelo teste de Tukey ( $\mathrm{p} \leq 0,05)$. 
Os maiores conteúdos de nutrientes foram observados na crotalária júncea e mucuna preta (Tabela 5), obtendo-se conteúdos de 221 e $180 \mathrm{~kg} \mathrm{ha}^{-1}$ de $\mathrm{N}$ e de 76 e $48 \mathrm{~kg} \mathrm{ha}^{-1}$ de K. Observam-se também os nutrientes das raízes os quais, apesar dos valores não serem muito elevados, induzem uma idéia de contribuição efetiva das leguminosas que, na sua grande maioria, possuem raízes pivotantes com grande capacidade de incorporar esses nutrientes em profundidade no solo. BARRADAs et al. (2001) constataram elevada contribuição de espécies de inverno quanto aos acúmulos de nitrogênio nas raízes, sendo o tremoço branco (Lupinus abus L) a espécie que mais acumulou massa seca e nitrogênio.

Caceres e Alcarde (1995) verificaram acúmulos de 235 e $102 \mathrm{~kg} \mathrm{ha}^{-1}$ de nitrogênio e potássio respectivamente para crotalária júncea. Na mucuna preta foi de 81 e $37 \mathrm{~kg} \mathrm{ha}^{-1}$, respectivamente, de nitrogênio e potássio. Esses resultados indicam o grande potencial de incorporação de nitrogênio e reciclagem de potássio por meio da mucuna preta e em especial pela crotalária júncea.

\section{Rendimento agrícola e industrial da cana- de-açúcar}

Houve incremento da produção de colmos da cana-deaçúcar, na média dos cinco cortes, em relação ao tratamento-testemunha (Tabela 6). Pode-se observar que o efeito do plantio de adubos verdes nas áreas de reforma do canavial promoveu benefícios em termos de aumento da produtividade da cana-de-açúcar. $\mathrm{O}$ tratamento com crotalária júncea destacou-se da testemunha na produtividade média de cinco anos. Possivelmente, a maior produção de matéria seca e acúmulo de nutrientes, espe- cialmente de $\mathrm{N}$ e de $\mathrm{K}$ influenciaram positivamente no crescimento do canavial.

Mascarenhas et al. (1994) evidenciaram o efeito positivo da adubação verde com crotalária júncea em canade-açúcar, com produtividade superior à aplicação ao solo de $40 \mathrm{~kg} \mathrm{ha}^{-1}$ de $\mathrm{N}$ via fertilizantes minerais.

Ambrosano et al. (2005) desenvolveram um experimento com cana-de-açúcar após rotação com crotalária júncea com adição conjunta e separada de adubação mineral de nitrogênio $\left(70 \mathrm{~kg} \mathrm{ha}^{-1}\right.$ de $\left.\mathrm{N}\right)$. Observaram que a cana-planta acumulou até o fim do primeiro corte quantidades de $\mathrm{N}$ semelhantes, provenientes tanto do fertilizante mineral (sulfato de amônio) quanto do adubo verde (crotalária júncea). Esse fato implica que a crotalária júncea supriu completamente as demandas da cana-planta em termos de $\mathrm{N}$, contudo, a utilização das duas fontes conjuntamente propiciou melhor desempenho da cana-de-açúcar em produção industrial.

Nos tratamentos que receberam o cultivo das leguminosas, previamente ao cultivo da cana-de-açúcar, foi menor a queda da produtividade até o terceiro corte comparado ao tratamento-testemunha (Tabela 6).

Ambrosano et al. (2010) trabalharam com sete espécies de plantas em rotação com cana-de-açúcar em áreas de reforma e verificaram aumentos na produção de açúcar em torno de 50\% nos tratamentos com girassol IACUruguai e de 35\% para crotalária júncea.

A queda na produtividade no decorrer dos anos do canavial é esperada e naturalmente ocorre, contudo a grande queda observada da soca 1 para a soca 2 foi motivada, também, pelas baixas precipitaçóes pluviais observadas nesse ano (1104 mm), quando comparadas ao ano anterior (1461 mm) (Tabela 6).

Tabela 6. Produtividade de colmos $\left(\mathrm{Mg} \mathrm{ha}^{-1}\right)$ e de açúcar aparente $(\mathrm{Mg}$ pol ha-1 $)$ da cana-de-açúcar influenciada pelo cultivo prévio de leguminosas (Piracicaba, 1999-2005)

\begin{tabular}{|c|c|c|c|c|c|c|}
\hline \multirow{2}{*}{$\begin{array}{l}\text { Culturas utilizadas } \\
\text { no pré-cultivo à cana }\end{array}$} & \multicolumn{6}{|c|}{ Produtividade de colmos } \\
\hline & Cana planta & Soca 1 & Soca 2 & Soca 3 & Soca 4 & Média \\
\hline Amendoim IAC-Caiapó & 122,7 & 122,3 & 67,4 & 49,4 & 36,8 & $79,7 \mathrm{AB}$ \\
\hline Crotalária júncea IAC 1 & 145,4 & 122,3 & 79,7 & 51,9 & 39,3 & $87,7 \mathrm{~A}$ \\
\hline Amendoim IAC-Tatu & 149,9 & 108,8 & 74,6 & 52,2 & 29,6 & $83,0 \mathrm{AB}$ \\
\hline Mucuna preta & 141,2 & 121,9 & 75,7 & 51,8 & 28,1 & $85,6 \mathrm{AB}$ \\
\hline Testemunha & 129,9 & 85,3 & 55,4 & 46,4 & 36,2 & $67,5 \mathrm{~B}$ \\
\hline \multirow[t]{2}{*}{ Média } & $138,4 \mathrm{a}$ & $113,2 \mathrm{~b}$ & $71,0 \mathrm{c}$ & $50,4 d$ & 34,2 e & \\
\hline & \multicolumn{6}{|c|}{ Produtividade açúcar aparente } \\
\hline Amendoim IAC-Caiapó & 18,7 & 18,7 & 10,2 & 7,7 & 6,2 & $12,3 \mathrm{AB}$ \\
\hline Crotalária júncea IAC 1 & 22,5 & 18,9 & 12,2 & 8,0 & 6,7 & $13,7 \mathrm{~A}$ \\
\hline Amendoim IAC-Tatu & 23,2 & 16,8 & 11,5 & 8,0 & 4,9 & $12,9 \mathrm{AB}$ \\
\hline Mucuna preta & 21,5 & 18,7 & 11,7 & 8,1 & 4,7 & $13,2 \mathrm{AB}$ \\
\hline Testemunha & 19,2 & 12,8 & 8,7 & 7,4 & 6,1 & $10,4 \mathrm{~B}$ \\
\hline Média & $21,2 \mathrm{a}$ & $17,4 \mathrm{~b}$ & $10,9 \mathrm{c}$ & $7,9 \mathrm{~d}$ & $5,7 \mathrm{e}$ & \\
\hline
\end{tabular}

$\mathrm{CV}(\%)($ parcela $)=7,57 ; \mathrm{CV}(\%)($ subparcela $)=4,20$ para TCH; $\mathrm{CV}(\%)($ parcela $)=25,80 ; \mathrm{CV}(\%)$ (subparcela) = 20,39 para produtividade de açúcar aparente (pol). Médias seguidas de mesma letra minúscula, nas linhas, e maiúsculas, nas colunas, nấo diferem entre si, pelo Teste de Tukey ( $>0.05$ ). Para fins de análise estatística os dados de produtividade de colmos foram transformados em $\log (\mathrm{x})$. Épocas de corte: cana planta $=25 / 10 / 2001$; soca $1=9 / 9 / 2002 ;$ soca $2=1 . \% / 8 / 2003$; soca $3=7 / 11 / 2004 ;$ soca $4=6 / 10 / 2005$. 


\section{Efeito do cultivo prévio de leguminosas sobre os nematoides Pratylenchus spp. na cultura da cana-de-açúcar}

Para o amendoim IAC-Caiapó o mínimo anotado foi de 10 nematoides por 10 gramas de raízes e o máximo de 470 , enquanto na testemunha essa variação foi de 80 para 2510 , indicando a menor presença do nematoide nos tratamentos com amendoim IAC-Caiapó (Figura 1).

Os nematoides das lesões (gênero Pratylenchus) são parasitos comuns de plantas em todo o mundo. São considerados, depois dos nematoides causadores de galhas (Meloidogyne spp.), como os parasitos que causam maiores perdas econômicas na agricultura mundial. Invadem o parênquima cortical das raízes, produzindo extensas áreas necróticas e causando sérias perdas econômicas. Pratylenchus brachyurus é um nematoide que ocorre com elevada frequência em culturas importantes do Brasil, como soja, café, cana-de-açúcar, algodão, entre outras.

O controle de P. brachyurus é bastante difícil e a busca por novas alternativas de manejo desse nematoide é complicada, pois é uma espécie com grande número de plantas hospedeiras, o que inviabiliza o uso da rotação de culturas; parece não existir fontes de resistência a $P$. brachyurus nas principais espécies vegetais cultivadas atualmente no Brasil. Além disso, o sucesso de programas de manejo de nematoides muitas vezes depende da rápida e segura identificação da espécie presente na área.

O cultivo prévio com espécies leguminosas ao da canade-açúcar pode ser um método eficiente em sistema integrado de controle dos fitos nematoides (Dinardo-Miranda e FraCASSO, 2009). É comum em algumas áreas, a prática do cultivo de fabáceas no período compreendido entre a destruiçáo das soqueiras de cana-de-açúcar e o plantio do novo canavial.

Várias são as plantas utilizadas em sistemas de rotação de culturas com cana-de-açúcar. As mais comuns são as crotalárias, a mucuna, a soja e o amendoim. Entretanto, dependendo das espécies de nematoides que ocorram na área de cultivo, algumas dessas culturas poderão aumentar sobremaneira a população desses parasitas. Por esse motivo, a cultura subsequente, no caso a cana-de-açúcar, poderá ser muito prejudicada pelo aumento do potencial de inóculo dos nematoides (NovaretTI, 1992).
Segundo Oliveira et al. (2008), a crotalária júncea semeada em áreas de reforma de canaviais infestados por Pratylenchus spp., proporcionou bom controle. Nas duas primeiras amostragens feitas 2 e 4 meses após o plantio da canade-açúcar as populaçóes de nematoides foram semelhantes ao tratamento com nematicida (150 gramas de aldicarbe por $\mathrm{kg}$ do produto comercial), na dosagem de $12 \mathrm{~kg} \mathrm{ha}^{-1}$ e também a utilização da soja (BRSGO Emgopa 316) em rotação.

As raízes de cana-de-açúcar com menor amplitude de ocorrência de nematoides Pratylenchus foram aquelas provenientes dos tratamentos após o cultivo dos amendoins, seguidos da mucuna preta, testemunha e da crotalária júncea (Figura 1).

Apesar da alta população de nematoides nas parcelas de cana-de-açúcar plantadas após o cultivo de crotalária júncea a produtividade física de colmos e a produçâo de açúcar não foram afetadas (Tabela 6).

\section{Análise econômica do cultivo prévio de leguminosas à cana-de-açúcar}

A maior renda foi obtida com o cultivo prévio de crotalária júncea, seguida pelo da mucuna preta (Tabela 7). O cultivo prévio dessas espécies gerou renda líquida de 156\% e 115\% maior que o tratamento-testemunha, respectivamente. A crotalária júncea utilizada na rotaçáo proporcionou vantagem econômica e baixo custo, tornando-se a melhor escolha.

Os amendoins IAC-Tatu e IAC-Caiapó proporcionaram um aumento de renda líquida quando comparados

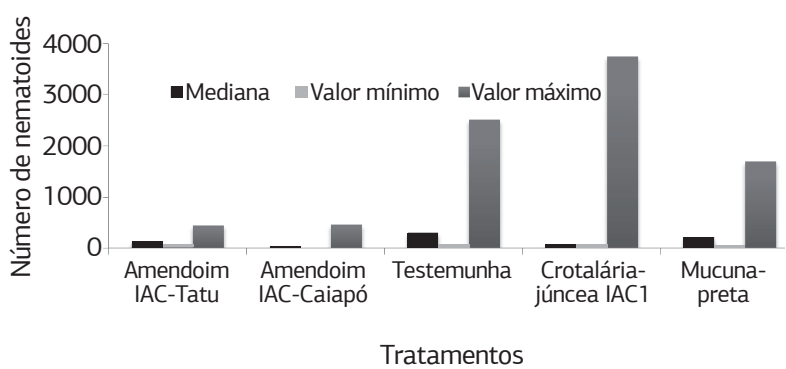

Figura 1. Número de nematoides do gênero Pratylenchus spp. por 10 gramas de raízes de cana-de-açúcar influenciados pelo cultivo prévio de espécies leguminosas.

Tabela 7. Balanço econômico $\left(\mathrm{R} \$ \text { ha }^{-1}\right)^{(1)}$ da produção de cana-de-açúcar instalada após o cultivo de espécies leguminosas (Piracicaba, 1999-2005)

\begin{tabular}{|c|c|c|c|}
\hline Culturas utilizadas no pré-cultivo à cana & Receita Total & Custos & Receita Líquida \\
\hline Amendoim IAC-Caiapó & 20730 a & 18902 a & $1828 a b$ \\
\hline Crotalária júncea IAC 1 & 20795 a & $17141 \mathrm{~b}$ & 3654 a \\
\hline Amendoim IAC-Tatu & $21882 \mathrm{a}$ & 18945 a & $2938 a b$ \\
\hline Mucuna preta & $19855 a b$ & $16787 b$ & $3068 \mathrm{ab}$ \\
\hline Testemunha & $16745 b$ & 15319 c & $1427 b$ \\
\hline Média & 20001 & 17419 & 2583 \\
\hline CV(\%) & 10,5 & 4,9 & 49,1 \\
\hline
\end{tabular}

Médias seguidas de letras diferentes diferem entre si, pelo teste de Tukey $(\mathrm{p} \leq 0,1)$.

${ }^{(1)}$ A receita total inclui a venda dos cinco cortes da cana-de-açúcar mais os grăos vindos da venda do amendoim. O custo da produção inclui o preparo do solo e manejo das culturas, produtos químicos, matérias-primas e os custos de colheita de todas as culturas, da cana e das utilizadas em pré-cultivo, mas exclui o aluguel das terras. 
com a testemunha de $105,9 \%$ e $28,14 \%$ respectivamente. Causaram também aumento no rendimento do colmo de cana em relação ao controle, principalmente na primeira colheita (Tabela 6), mas o alto custo de produção desse grão anula o benefício econômico dessa rotação. No entanto, em muitas regiōes canavieiras no Estado de São Paulo, amendoins são amplamente cultivados em rotação com a cana, provavelmente porque nesses locais os rendimentos são mais elevados e os custos de produção mais baixos.

Ambrosano et al. (2010) trabalharam com as mesmas cultivares empregadas nesses estudos e com exceçáo dos amendoins, com renda líquida igual ao tratamento-testemunha, todas as outras espécies aumentaram a renda líquida. A menor renda líquida obtida com os amendoins pelos autores citados em comparaçáo a este estudo pode ser atribuída à menor produtividade obtida e o menor preço de venda.

\section{CONCLUSÃO}

Há um incremento na produtividade física e de açúcar da cana, na média de cinco colheitas, quando se efetua o cultivo prévio de crotalária júncea à cana planta. A crotalária júncea proporciona a melhor relação custo-benefício para ser usada em cultivo prévio à instalação do canavial, destacandose em relação à produçáo de material vegetal e ao acúmulo de nutrientes, em especial ao de N. A menor população de Pratylenchus spp. nas raízes da cana-de-açúcar é observada nos tratamentos com cultivo prévio do amendoim à cana planta.

\section{AGRADECIMENTOS}

Ao CNPq pelo apoio (bolsa de produtividade em pesquisa do primeiro autor).

\section{REFERÊNCIAS}

AMBROSANO, E.J; TRIVELIN, P.C.O.; CANTARELLA, H.; AMBROSANO, G.M. B.; SCHAMMASS, E.A.; MURAOKA, T.; ROSSI, F.; $15 \mathrm{~N}$-labeled nitrogen from green manure and ammonium sulfate utilization by the sugarcane ratoon. Scientia Agricola, v.68, p.361-368, 2011.

AMBROSANO, E.J.; TRIVELIN, P.C.O.; CANTARELLA, H.; AMBROSANO, G.M.B.; SCHAMMASS, E.A.; GUIRADO, N.; ROSSI, F.; MENDES, P.C.D. MURAOKA, T. Utilization of nitrogen from green manure and mineral fertilizer by sugarcane. Scientia Agricola, v.62, p.534-542, 2005.

AMBROSANO, E.J.; AZCÓN R.; CANTARELLA, H.; AMBROSANO, G.M.B.; SCHAMMASS, E.A.; TRIVELIN, P.C.O.;MURAOKA, T; ROSSI, F.; GUIRADO, N.; UNGARO, M.R.G.; TERAMOTO J.R.S. Crop rotation biomass and arbuscular mycorrhizal fungi effects on sugarcane yield. Scientia Agricola, v.67, p.692-701, 2010.
AMBROSANO, E.J.; WUTKE, E.B.; BRAGA, N.R.; MIRANDA, M.A.C. Leguminosas: alternativas para produção ecológica de grãos em diferentes regiôes agroecológicas do Estado de São Paulo. In: AMBROSANO, E.J. (Coord.). Agricultura Ecológica. 1.ed. Guaíba: Agropecuária, 1999. p.161-178.

BANCO IEA. 2010. Instituto de Economia Agrícola. [cited 2010 May 28]. Available from: HTTP://www.iea http://ciagri.iea.sp.gov. br/nia1/Precos_Medios.aspx?cod_sis=2.

BATAGLIA, O.C.; FURLANI,A.M.C.;TEIXEIRA; J.P.F.; FURLANI, P.R.; GALLO, J.R. Métodos de análises químicas de plantas. Campinas: Instituto Agronômico, 1983. 48p. (Boletim Técnico, 78)

BARRADAS, C.A.A.; FREIRE, L.R.; ALMEIDA, D.L.; DEPOLLI, $\mathrm{H}$. Comportamento de adubos verdes de inverno na região serrana fluminense. Pesquisa Agropecuária Brasileira, v.36, p.14611468,2001

CACERES, N.T.; ALCARDE, J.C. Adubação verde com leguminosas em rotação com cana-de-açúcar (Saccharum ssp). STAB, v.13, p.16-20, 1995.

COOLEN, W.A.; D'HERDE, C.J. A method for the quantitative extraction of nematodes from plant tissue. Ghent: State Nematology and Entomology Research Station, 1972.77p.

DINARDO-MIRANDA, L.L.; FRACASSO, J.V. Spatial distribution of plant-parasitic nematodes in sugarcane fields. Scientia Agricola, v.66, p.188-194, 2009.

GIOVANETTI, M.; MOSSE, B. An evaluction of techniques for measuring vesicular arbuscular mycorrhizal spores. New Phytologist, v.84, p.489-500, 1980.

HOOPER, D.J. Handling, fixing, staining, and mounting nematodes. In: SOUTHEY, J.F. (Ed.). Laboratory Methods with Nematodes. London: Her Majesty's Stationery Office, 1970. p.5-30.

HUYNH, H.; FELDT, L.S. Conditions under which mean square rations in repeated measurements designs have exact F-distributions. Journal of the American Statistical Association, v.65, p.1582-1589, 1970 .

IGUE, K. Dinâmica da material orgânica e seus efeitos na propriedade do solo. In: Fundação Cargill (Ed.). Adubação verde no Brasil. Campinas: Fundação Cargill, 1984. p.232-267.

INOMOTO, M.M., MOTTA, L.C.C., BELUTI, D.B., MACHADO, A.C.Z. Reação de seis adubos verdes a Meloidogyne javanica e Pratylenchus brachyurus. Nematologia Brasileira, v.30, p.39-44, 2006.

JENKINS, W.R. A rapid centrifugal-flotation technique for separating nematodes from soil. Plant Disease Reporter, v.48, p.692, 1964.

LUZ, P.H.C; VITTI, G.C.; QUINTINO, T.A.; OLIVEIRA, D.B. Utilização da Adubação Verde na Cultura da Cana-de-Açúcar. Piracicaba: ESALQ, GAPE - Departamento de Solos e Nutrição de Plantas, 2005. 53p.

MACHADO, A.C.Z., MOTTA L.C.C., SIQUEIRA K.M.S., FERRAZ L.C.C.B., INOMOTO M.M. Host status of green 
manures for two isolates of Pratylenchus brachyurus in Brazil. Nematology, v.9, p.799-805, 2007.

MARTINS, R. Amendoim: safra 2008/09 e perspectiva para 2009/10. Análise e Indicadores dos Agronegócios, v.5, jan.2010. [cited 2010 May 28]. Available from: http://www.iea.sp.gov.br/ out/verTexto.php? $\operatorname{cod}$ Texto $=11831$.

MASCARENHAS, H.A.A.; TANAKA, R.T.; COSTA, A.A.; ROSA, F.V.; COSTA, V.F. Efeito residual das leguminosas sobre o rendimento físico e econômico da cana-planta, Campinas: Instituto Agronômico, 1994. 15p. (Boletim Científico, 32)

MAUCHLY, J.W. Significance test for sphericity of a normal n-variate distribution. Annals of Mathematical Statistics, v.11, p.204-209, 1940.

NOVARETTI, W.R.T. Nematóides em cana-de-açúcar e seu controle. Informe Agropecuário, v.16, p.37-42. 1992.

OLIVEIRA E.S.; ROCHA M.R.; TEIXEIRA R.A.; FALEIRO V.O.; SOARES R.A.B. Efeito de Sistemas de Cultivo no Manejo de Populações de Pratylenchus spp. na Cultura da Cana-de-açúcar. Nematologia Brasileira, v.32, p.117-125. 2008.

PANJA, B.N.; CHAUDHURI S. Exploitation of soil arbuscular mycorrhizal potential for AM-dependent mandarin orange plants by pre-cropping with mycotrophic crops. Applied Soil Ecology, v.26, p.249-255, 2004.

PERIN, A.; SANTOS, R.H.S.; URQUIAGA, S.; GUERRA, J.G.M.; CECON, P.R. Sunnhemp and millet as green manure for tropical maize production. Scientia Agricola, v.63, p.453-459, 2006.

PHILIPS, J.M.; HAYMAN, D.S. Improved procedures for cleaning roots and staining parasitic and vesicular arbuscular mycorrhizal fungi for rapid assessment of infection. Transactions of the British Mycological Society, v.55, p.158-162, 1970.

QUAGGIO, J.A.; GODOY, I.J. Amendoim. In: RAIJ, B. van; CANTARELlA, H.; QUAGGIO, J.A.; FURLANI, A.M.C. Recomendações de adubação e calagem para o Estado de São Paulo. 2.ed. Campinas: IAC, 1996. p.192 (Boletim Técnico, 100)

SAS INSTITUTE. SAS/STAT software: changes and enhancements through release 8.2. Cary: SAS Institute, Cary, NC, USA, 2004. 1028p.

SCIVITTARO, W.B.; MURAOKA, T.; BOARETTO, A.E.; TRIVELIN, P.C.O. Utilizaçâo de nitrogênio de adubos verdes e mineral pelo milho. Revista Brasileira de Ciência do Solo, v.24, p.917-926, 2000.

SHEARER, W.B.; KOHL, D.H. $\mathrm{N}_{2}$-fixation in field settings: estimations based on natural ${ }^{15} \mathrm{~N}$ abundance. Australian Journal of Plant Physiology, v.13, p.699-756, 1986.

TANIMOTO, T. The press method of cane analysis. Hawaiian Planter's Record, v.57, p.133-150, 1964.

TRIVELIN, P.C.O.; SALATI, E.; MATSUI, E. Preparo de amostras para análise de $15 \mathrm{~N}$ por espectrometria de massas. Piracicaba: USP/ CENA, 1973. 41p. (Boletim Técnico, 2)

UNIÃO DOS PRODUTORES DE BIOENERGIA. UDOP. [cited 2010 May 28]. Available from: http:/www.udop.com.br.

WANG, K.H.; SIPES B.S.; SCHMITT, D.P. Crotalaria as a cover crop for nematode management. Nematropica, v.32, p.35$57,2002$. 